\title{
Diamide-Induced Alterations of Intracellular Thiol Status and the Regulation of Glucose Metabolism in the Developing Rat Conceptus In Vitro
}

\author{
ROONGRUDEE HIRANRUENGCHOK AND CRAIG HARRIS \\ Toxicology Program, Department of Environmental and Industrial Health, School of Public Health, University of \\ Michigan, Ann Arbor, Michigan 48109
}

\begin{abstract}
Direct oxidation of embryonic reduced glutathione (GSH) by a thiol oxidant, diamide, has been demonstrated to result in increased glutathione disulfide (GSSG) and proteinglutathione mixed disulfide (protein-S-SG) formation, which is accompanied by embryotoxicity and reductions in amniotic fluid volume. The altered functions of critical proteins or enzymes caused by the formation of protein-S-SG perturb cellular metabolism and may be involved in the embryotoxicity produced by GSH oxidation. The present study investigates changes in the metabolism of glucose through glycolysis and the pentose phosphate shunt pathways (PPP) and their related enzymes under the oxidative conditions produced by diamide exposure in organogenesis-stage rat conceptus (gestational day 10) in vitro. The metabolism of glucose via the PPP, measured as amounts of $\mathrm{CO}_{2}$ production from $\mathrm{D}-\left[1-{ }^{14} \mathrm{C}\right]$-glucose, was significantly increased in the conceptus exposed to 100-500 $\mu \mathrm{M}$ diamide to levels 2.5-3-fold those of controls. It was found that these substantial increases in the PPP activity did not correlate well with a moderate activation of glucose 6-phosphate dehydrogenase (G6PD) activity, the key enzyme in the PPP pathway. Changes in glycolysis due to diamide treatment were also determined by measurements of lactate production from D-[U- $\left.{ }^{14} \mathrm{C}\right]$ glucose. Production of lactate by the conceptus exposed to 250-500 $\mu \mathrm{M}$ diamide for $60 \mathrm{~min}$ was reduced (to approximately $54 \%$ of control values) concomitantly with a significant inhibition of the glycolytic enzymes, glyceraldehyde 3-phosphate dehydrogenase (GPD) and phosphofructokinase (PFK), indicating an overall decrease in glycolysis. Diamide was found to produce a differential effect on the enzymatic activities determined in this study, with greater degrees of inhibition seen in the tissue supernatants from the visceral yolk sac (VYS) compared to those from the embryo. Activities of GPD and PFK were decreased to approximately $22 \%$ and $43 \%$ control values, respectively, when determined in the supernatants from the VYS of the con-
\end{abstract}

ceptus exposed to $500 \mu \mathrm{M}$ diamide for $60 \mathrm{~min}$. In addition, more than $90 \%$ of the GPD activity in the VYS, but not the embryo, was rapidly inhibited by the thiol alkylating agent $N$-ethylmaleimide (NEM, $100 \mu \mathrm{M}$ ) within 15 min of the exposure. In contrast to diamide and NEM, no alterations in lactate production were seen in the conceptus treated with the GSH depletor L-buthionine-S,R-sulfoximine (1 $\mathrm{mM})$ for $5 \mathrm{hr}$ in the culture media. Further experiments demonstrated that the activity of the GPD, inhibited by a 30-min incubation with $500 \mu \mathrm{M}$ diamide, can be reversed after removal of diamide and that this effect was potentiated by subsequent treatment with dithiothreitol $(30 \mathrm{mM})$, a thiol reducing agent. These results indicated the involvement of thiol/disulfide status in regulation of the metabolism of glucose in the developing conceptus and support the hypothesis that GSH oxidation and proteinS-SG formation could be a critical event associated with mechanisms of embryotoxicity elicited by oxidative stress. It was suggested in this study that, under these experimental conditions, embryotoxicity induced by diamide is primarily mediated via altered VYS functions, including disrupted energy production (glycolysis). (c) 1995 Wiley-Liss, Inc.

Reduced glutathione (GSH) has been shown to be involved in several important cellular functions includ-

Abbreviations: BSO, L-buthionine-(S,R)-sulfoximine; DPM, disintegrations per min; DTT, dithiothreitol; F-1,6-B, fructose 1,6-biphosphatase; GD, gestational day; G6PD, glucose 6-phosphate dehydrogenase; GPD, glyceraldehyde 3-phosphate dehydrogenase; GSSG, glutathione disulfide; GSH, reduced glutathione; GSSG-reductase, glutathione disulfide reductase; HBSS, Hanks' balanced salt solution; NEM, $N$-ethylmaleimide; LSC, liquid scintillation counting; PFK, phosphofructokinase; PK, pyruvate kinase; PPP, pentose phosphate shunt pathway; protein-S-SG, protein-glutathione mixed disulfide.

Received February 20, 1995; accepted August 31, 1995.

Address reprint requests to Dr. Craig Harris, Toxicology Program, Department of Environmental and Industrial Health, University of Michigan, 1420 Washington Heights, Ann Arbor, MI 48109-2029. 
ing its major role in cellular protection against reactive intermediates (Kosower and Kosower, '78; Jones et al., '86). Studies have shown that GSH-dependent mechanisms, which are protective against several embryotoxins/teratogens, are present in developing mammalian conceptuses and that modulation of GSH levels resulted in alterations of embryotoxicities elicited by a number of chemicals (Harris et al., '87, '88; Wong et al., '89). As an antioxidant, GSH is known to be used as a cofactor for GSH peroxidase in the removal of hydrogen peroxide $\left(\mathrm{H}_{2} \mathrm{O}_{2}\right)$, preventing subsequent formation of the highly reactive hydroxyl radicals $(\cdot \mathrm{OH})$. Hydroxyl radicals are suggested to be the most reactive oxygen species which can damage cells. In the GSH peroxidase-mediated reaction, GSH is converted to its oxidized form, glutathione disulfide (GSSG) (Jones et al., '86). Changes in GSH and GSSG status, as a consequence of detoxification, may lead to toxicity directly due to alterations of cellular function, especially when cellular counteracting systems such as glutathione disulfide reductase (GSSG-reductase) activities are overwhelmed. Effects of GSH oxidation on cellular function may be mediated by changes in protein structure and enzymatic activity, which are regulated by thiol/disulfide exchange. Several enzymes contain sulfhydryl groups essential for their activities and a number of these enzymes have been shown in vitro to be activated or inactivated by biological disulfides such as GSSG, CoASSG, or cysteamine disulfide (Brigelius, '85; Gilbert, '82, '84). These effects can normally be reversed by reducing agents such as dithiothreitol or mercaptoethanol. The (in)activation of enzymes by the disulfide may result from formation of a mixed disulfide with the proteins, a process referred to as protein S-thiolation, via a thiol-disulfide exchange. Glutathione, the most abundant low-molecular-weight thiol in cells, will produce this form of protein-glutathione mixed disulfide (protein-S-SG) in much higher concentrations when compared to other forms of protein-thiol mixed disulfides.

Among the enzymes for which activities may be controlled by thiol-disulfide exchange, those involved in carbohydrate metabolism have been most extensively characterized (Gilbert, '82, '84). In these studies, mostly with purified enzymes, activation and inactivation of the enzymes through direct or indirect reaction with GSSG and other biological disulfides have been demonstrated. The pattern of this regulation suggests that S-thiolation of proteins may have an integrated controlling function in glucose metabolism. If this were to occur in biological systems, it would result in inhibition of glycolysis and glycogen synthesis, activation of gluconeogenesis and glycogenolysis, and particularly increased flux of glucose 6-phosphate through the pentose phosphate shunt pathway (PPP). Increased PPP activity is an important compensatory response, allowing for the generation of NADPH-reducing equivalents, which are important in the protection of cells against oxidative conditions. Oxidative stress induced by several thiol oxidants, such as diamide, $\mathrm{H}_{2} \mathrm{O}_{2}$, or $t$-butylhydroperoxide, has been shown to stimulate the oxidation of GSH to GSSG and increase the PPP activity in a variety of cultured cells or isolated organs (May, '81; Brigelius, '83; Brigelius and Schult, '84). Glutathione disulfide has been implicated to play a significant role in regulation of the PPP either through the formation of a mixed disulfide with glucose 6-phosphate dehydrogenase (G6PD), the key enzyme in the PPP, or via a coupled change in NADPH/NADP ${ }^{+}$status due to NADPH utilization in GSSG reduction (Eggleston and Krebs, '74; Levy and Christoff, '83; Brigelius and Schult, '84).

Although accumulated evidence has demonstrated the possible roles of GSH oxidation in modulation of enzymatic activities and metabolism of glucose via thiol/disulfide exchange, these effects have not been directly investigated in developing mammalian conceptuses. It has been shown that the PPP in the early organogenesis stage conceptuses is active and that conceptuses at this stage depend heavily on glycolysis for energy production (Tanimura and Shepard, '70). According to this evidence, it may be possible that GSH oxidation and increased protein-S-SG formation in the conceptal tissues would result in changes in glucose metabolism. Direct alterations of these pathways may lead to embryotoxicity independent of other chemical interactions.

The purpose of this study was to investigate changes in the metabolism of glucose through the pentose phosphate shunt and glycolytic pathways under the oxidative conditions elicited by diamide. Alterations in the activities of key metabolic enzymes shown to be controlled by thiol-disulfide exchange were examined, including G6PD, glyceraldehyde 3-phosphate dehydrogenase (GPD), and phosphofructokinase (PFK). G6PD is the enzyme catalyzing the first reaction in the PPP. Both GPD and PFK are enzymes regulating two different reactions in the glycolytic pathway. These enzyme activities are known to be modified by addition of biological disulfides or thiol oxidants and vulnerable to conditions of oxidative stress. Incubation of rabbit muscle phosphofructokinase with GSSG resulted in a rapid inactivation of the enzyme activity, probably via mixed disulfide formation with glutathione (Gilbert, '82). It was also recently shown that GPD was inhibited by S-thiolation upon $\mathrm{H}_{2} \mathrm{O}_{2}$ exposure in human endothelial cells (Schuppe-Koistinen et al., '94). Moreover, there are strong indications that a close relationship exists between G6PD and protein-S-SG in tissues of isolated perfused rat livers challenged by redox cycling compounds or by $t$-butylhydroperoxide (Brigelius and Schult, '84). This study provides information to support the role of GSH and formation of the proteinS-SG in regulation of glucose metabolism via the PPP and glycolysis in early organogenesis stage rat conceptuses. 


\section{MATERIALS AND METHODS Chemicals}

Diamide, L-buthionine-S,R-sulfoximine (BSO), dithiothreitol (DTT), $N$-ethylmaleimide (NEM), and benzethonium hydroxide were purchased from Sigma Chemical Co., St. Louis, MO. D- $\left[1-{ }^{14} \mathrm{C}\right]$-glucose and $\mathrm{D}-\left[\mathrm{U}-{ }^{14} \mathrm{C}\right]$-glucose were provided by Amersham Co. (Arlington Heights, IL). All other chemicals and reagents were of purest grade commercially available.

\section{Animals}

Time-mated primagravida Sprague-Dawley rats were obtained from the Reproductive Science Program Small Animal Core Facility, the University of Michigan, on gestational day (GD) 7-9. The morning following copulation, as indicated by the presence of a spermpositive vaginal smear, was designated as GD 0 . Pregnant rats were maintained on a 14-hr light/10-hr dark cycle and given free access to food and water until the morning of explantation.

\section{Rat whole embryo culture}

On the morning of GD 10, pregnant dams were anesthetized with ether and blood was collected from the abdominal aorta. The blood was centrifuged and serum was heat-inactivated and used for preparation of culture media. Uteri were removed and placed in sterile Hanks' balanced salt solution (HBSS) where the implantation sites were dissected free. Conceptuses prepared for culture were carefully separated from decidual mass and Reichert's membrane. The conceptuses, consisting of the visceral yolk sac (VYS), ectoplacental cone (EPC), and embryo proper, were cultured in media containing $33 \%$ heat-inactivated female rat serum in HBSS supplemented with penicillin $\mathrm{G}(41 \mathrm{IU} / \mathrm{ml})$ and streptomycin $(41 \mu \mathrm{g} / \mathrm{ml})$. The media had been previously warmed and gassed with $20 \% \mathrm{O}_{2} / 5 \% \mathrm{CO}_{2} / 75 \% \mathrm{~N}_{2}$ prior to addition of conceptuses. The culture bottles were placed on a roller incubator, and the conceptuses were cultured at $37^{\circ} \mathrm{C}$ throughout the culture period. Conceptuses were allowed to equilibrate in the culture media for approximately $1 \mathrm{hr}$ prior to addition of test chemicals directly to the culture media.

Following each treatment, conceptuses were removed from the media and tissues were prepared in the appropriate buffers for each biochemical assay. The tissues were stored at $-74^{\circ} \mathrm{C}$ until used for biochemical analysis. Protein content was determined using the method of Bradford ('76), as modified for use with a 96-well plate and analyzed in a microtitre plate spectrophotometer. Bovine plasma $\gamma$-globulin was used for preparation of the standard curve.

\section{Determination of lactate content in conceptuses}

Five conceptuses (GD 10) were cultured in $5 \mathrm{ml}$ media in the presence and absence of the chemicals described in Figure 1. After the treatments at indicated times, the conceptuses were taken from the media, rinsed with three changes of HBSS, and transferred to a dish containing fresh HBSS. Each conceptus was then harvested with $50 \mu l$ of HBSS and placed in a microcentrifuge tube containing $75 \mu \mathrm{l}$ of $3 \mathrm{~N} \mathrm{HClO}_{4}$. The samples were immediately frozen with liquid nitrogen and stored at $-74^{\circ} \mathrm{C}$. For analysis, thawed samples were homogenized by ultrasonic disruption and the samples were diluted by addition of $200 \mu$ lice-cold distilled $\mathrm{H}_{2} \mathrm{O}$. The precipitated conceptal protein was separated by centrifugation and the protein-free supernatant was neutralized with excess $\mathrm{KHCO}_{3}$. After $\mathrm{KClO}_{4}$ was removed by centrifugation, the lactate contents were measured in the supernatant fluid using the fluorimetric method described by Passonneau ('74).

\section{Determinations of enzymatic activities}

Following incubation of the conceptuses in control media or in media containing $N$-ethylmaleimide (NEM) or diamide, conceptuses were removed from the media, rinsed three times with ice-cold PBS (to minimize artifactual alterations of thiol-disulfide bonds during workup). Embryos and VYS were isolated, pooled and placed in PBS. The samples were quickly frozen with liquid nitrogen and kept at $-74^{\circ} \mathrm{C}$ until used for assays. For analysis of the enzymatic activities, tissues supernatants were prepared by centrifugation $(14,000 \mathrm{~g}, 10 \mathrm{~min})$ of homogenates previously obtained by ultrasonic disruption, and kept on ice at all times. GPD (Birkett, 73), phosphofructokinase (Gilbert, '82), and G6PD (Lee, '82) activities were determined individually in tissue supernatants from both the embryo and VYS using spectrophotometric methods. The enzymatic activities are measured by changes in absorbance at $340 \mathrm{~nm}$ of the pyridine nucleotides used in each assay.

\section{Determination of pentose phosphate shunt pathway activity}

Pentose phosphate shunt pathway (PPP) activity was determined from rates of ${ }^{14} \mathrm{CO}_{2}$ production by using $\mathrm{D}-\left[1-{ }^{14} \mathrm{C}\right]$-glucose as substrate, as previously described by Horton et al. ('85). At the appropriate times, conceptuses were transferred from the original culture media to specially designed culture bottles. These culture bottles were designed to have a separate center well for trapping $\mathrm{CO}_{2}$ and an outer compartment for culture media. Five conceptuses were cultured in 2.5 $\mathrm{ml}$ of standard media which had been gassed with $20 \%$ $\mathrm{O}_{2}, 5 \% \mathrm{CO}_{2}$ previously. Diamide, at various concentrations, was added directly to the media containing trace amounts of $\mathrm{D}-\left[1{ }^{14} \mathrm{C}\right]$-glucose $(1 \mu \mathrm{Ci} /$ culture $)$. After addition of $\left[{ }^{14} \mathrm{C}\right]$-glucose, $20 \mu \mathrm{l}$ of the media was added to $6 \mathrm{ml}$ liquid scintillation counting (LSC) cocktail (Biosafe II, RPI) and counted for radioactivity (determined as disintegrations per min, DPM) measured in a Beckman LS6000IC liquid scintillation counter. Since only trace amounts of labeled glucose were added, the 

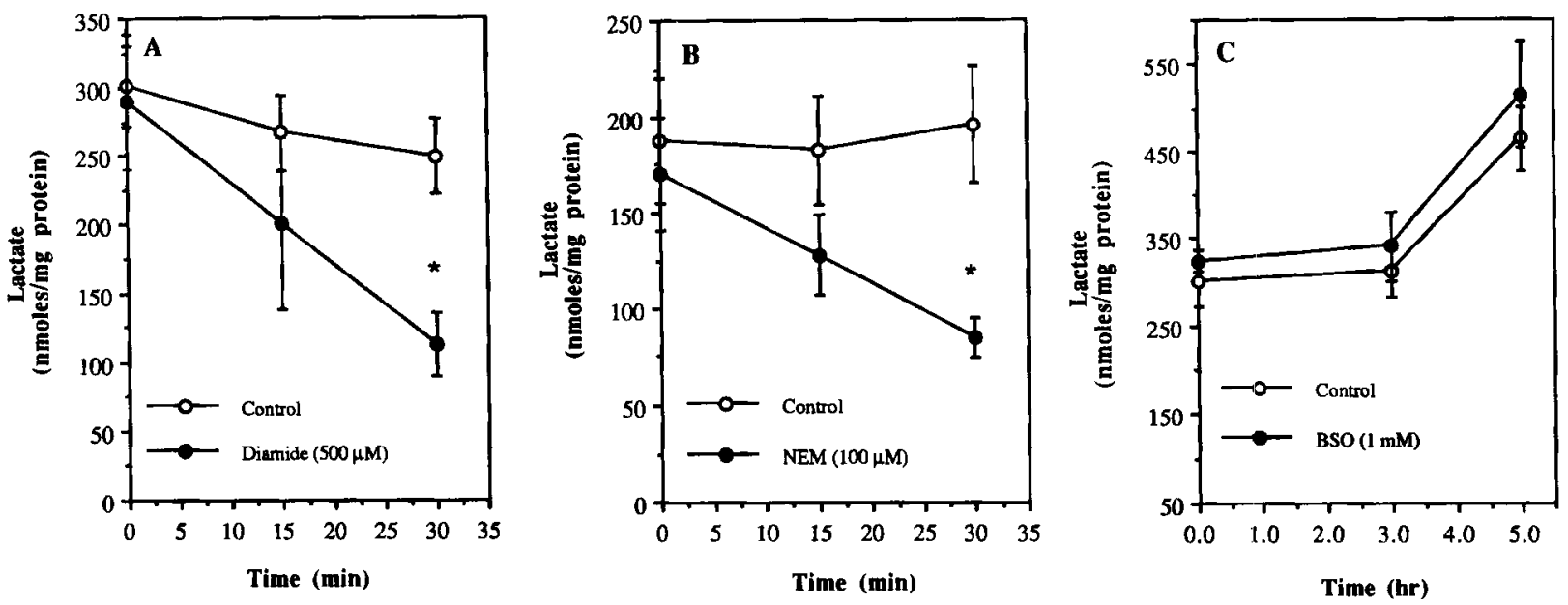

Fig. 1. Lactate levels in rat conceptuses (GD 10) following treatments with intracellular thiol-modulating agents. Five conceptuses were cultured in $5 \mathrm{ml}$ media with or without addition of diamide (500 $\mu \mathrm{M}, \mathbf{A}), N$-ethylmaleimide (NEM, $100 \mu \mathrm{M}, \mathrm{B}$ ), or L-buthionine-(S,R)-sulfoximine (BSO, $1 \mathrm{mM}, \mathrm{C}$ ). Following the indicated incubation periods, the culture was terminated, and the conceptuses were removed and rinsed with HBSS to free of media. Total lactate was determined in each whole conceptus as described in the method. Values are means $\pm S E$ ( $n=7-10$ from two separate, identical experiments). Asterisk $(*)$, statistically significant difference from control when $P \leq 0.05$.

specific activity of $\left[{ }^{14} \mathrm{C}\right]$-glucose in the media for each sample (approx. 150,000 dpm/ $\mu \mathrm{mol}$ glucose) was determined from DPMs of $\left[{ }^{14} \mathrm{C}\right]$-glucose and the concentration of unlabeled glucose in the media. Concentrations of glucose were determined by spectrophotometry using a Glucose Diagnostic Kit (Trender; Sigma). The concentrations of glucose in the media were found to vary slightly among different batches of serum (approximately 6-9 mM). However, the same lot of culture media was used for all incubations in each experiment. The bottles were tightly sealed with rubber sleeve stoppers and placed in a rotator incubator. Subsequent additions of chemicals to the culture medium were made by injection through the stoppers without release of the enclosed gas phase. Conceptuses were incubated for $1 \mathrm{hr}$ in the presence of $\left[{ }^{14} \mathrm{C}\right]$-glucose in control and diamide-supplemented media. Following the incubation period, the culture bottles were removed from the incubator and $0.3 \mathrm{ml}$ of benzethonium hydroxide was added to the center well of the culture bottle to trap $\mathrm{CO}_{2}$ and $0.3 \mathrm{ml}$ of $6 \mathrm{~N} \mathrm{H}_{2} \mathrm{SO}_{4}$ was injected into the culture media to release the dissolved $\mathrm{CO}_{2}$. The bottles were placed in a shaking water bath $\left(37^{\circ} \mathrm{C}\right)$ for an additional $1 \mathrm{hr}$ to evolve fully and trap the $\mathrm{CO}_{2}$ produced. A $0.2-\mathrm{ml}$ aliquot of benzethonium hydroxide was then removed from the center well and placed into $6 \mathrm{ml}$ of BioSafe LSC cocktail for determination of radioactivity.

\section{Determination of glycolysis}

Approximately 8 conceptuses were cultured in a roller bottle containing $3 \mathrm{ml}$ culture media in the pres- ence and absence of diamide. The culture media was previously gassed as described above. U-[ $\left.{ }^{14} \mathrm{C}\right]$-glucose was added to the media to obtain a final concentration of $1.5 \mu \mathrm{Ci} /$ culture and specific activity of approximately $200,000 \mathrm{dpm} / \mathrm{mmole}$ determined as described above for analysis of PPP activity. Conceptuses were incubated for a $1-\mathrm{hr}$ period and the media $(1 \mathrm{ml})$ was removed to determine radioactivity of the lactate fraction. Lactate was isolated from the media after culture by the method of Barker and Summerson ('41) as previously described by Horton et al. ('85). Briefly, $1 \mathrm{ml}$ of media was deproteinized by adding an equal volume of $20 \%$ trichloroacetic acid (TCA). The precipitated protein was removed by centrifugation; $1 \mathrm{ml}$ of the supernatant was added to $1 \mathrm{ml}$ of $20 \% \mathrm{CuSO}_{4}$ and the total volume was brought up to $10 \mathrm{ml}$ by the addition of distilled water. After an immediate addition of one gram of $\mathrm{Ca}(\mathrm{OH})_{2}$, the solution was quickly vortexed. The mixture was allowed to sit at room temperature for 30 min with occasionally mixing and then centrifuged to obtain a clear supernatant. A $500-\mu$ l aliquot of the supernatant containing radiolabeled lactate was placed into $6 \mathrm{ml}$ of LSC cocktail for measurement of radioactivity. For determination of lactate formation in the conceptus, all conceptuses in the culture plus $1 \mathrm{ml}$ of the media were removed, homogenized by ultrasonic disruption, and subjected to the extraction process, as described above. Radioactivity of $\left[{ }^{14} \mathrm{C}\right]$-lactate in the conceptuses was determined by subtracting the DPMs in the fraction extracted from conceptuses plus media by that extracted from media alone. 


\section{Analysis of $\mathrm{CO}_{2}$ and lactate production}

Background DPMs due to nonspecific degradation of labeled glucose substrates were concurrently determined in the ${ }^{14} \mathrm{CO}_{2}$ containing benzethonium hydroxide and $\left[{ }^{14} \mathrm{C}\right]$-lactate fractions from cultures where no conceptuses were added. The background counts were subtracted from the DPMs in the corresponding fractions recovered from conceptuses containing cultures prior to subsequent calculation of moles of the products. Since cold glucose is assumed to be used in the same manner as labeled glucose, the total moles of glucose used via $\mathrm{CO}_{2}$ or lactate production was calculated by dividing the total DPMs of ${ }^{14} \mathrm{CO}_{2}$ in the benzethonium hydroxide fraction or of $\left[{ }^{14} \mathrm{C}\right]$-lactate in the culture media or in the conceptuses by the specific activity of the $\left[{ }^{14} \mathrm{C}\right]$ glucose added to the culture media. Assuming that $\left[{ }^{14} \mathrm{C}\right]$ was equally labeled, nmoles of utilized glucose were then stoichiometrically converted to nmoles of $\mathrm{CO}_{2}$ or lactate produced. The amounts of the $\mathrm{CO}_{2}$ and lactate produced were normalized to protein. For determination of protein content of the conceptus, conceptuses of identical developmental stages were cultured under the same experimental conditions for both control and treatment groups except that no $\left[{ }^{14} \mathrm{C}\right]$-glucose was added.

\section{Statistical analysis}

Statistical differences between treatments were determined using analysis of variance (ANOVA); General Linear Model Procedure (SAS). Differences were considered to be statistically significant when $P \leq 0.05$.

\section{RESULTS}

Previous reports (Hiranruengchok and Harris, '93, '95) have shown that diamide $(75-500 \mu \mathrm{M})$ elicits concentration-dependent effects resulting in oxidation of reduced glutathione (GSH) and increased protein-glutathione mixed disulfide (protein-S-SG) formation in organogenesis-stage rat conceptuses on gestational day 10 (GD 10). Oxidation of intracellular GSH produced embryotoxicity in cultured conceptuses (GD 11) following either long or short-term exposure to diamide. Based on these results, identical treatment levels were used in the present study to determine the biochemical responses of the developing conceptuses to diamide exposure with respect to changes in metabolism of glucose via the pentose phosphate shunt pathway (PPP), glycolysis (Embden-Meyerhof pathway), or related enzymatic activities. Because the Krebs cycle and electron transport systems are believed to be immature at this stage of development (GD 10), measurements of $\mathrm{CO}_{2}$ and lactate production from $1-\left[{ }^{14} \mathrm{C}\right]$-glucose and $\mathrm{U}-\left[{ }^{14} \mathrm{C}\right]$-glucose provide accurate assessments of the activities of the PPP and glycolysis pathways, respectively (Shepard et al., '70).

The data in Table 1 demonstrate that rat conceptuses (GD 10) used a high proportion of glucose via glycolysis relative to the oxidative PPP (1122.0 nmoles glucose $/ \mathrm{mg}$ protein and $14.0 \mathrm{nmoles}$ glucose $/ \mathrm{mg}$ protein, respectively) as reported previously by Tanimura and Shepard ('70). Following a 1-hr culture period, exposure of the conceptuses to diamide $(50-500 \mu \mathrm{M})$ exhibited activation of the PPP in a concentration-dependent manner. Significant increases in the PPP (approximately 2.5-3-fold those of control values) were observed in the conceptuses exposed to diamide at concentrations of $100 \mu \mathrm{M}$ or greater. This is the same dose range for which tissue thiol oxidation and impaired development were observed (Hiranruengchok and Harris, '93, '95). The results also showed that most of the lactate was released into culture media while relatively little accumulated in the conceptus. That which did remain probably accumulated in tissues and especially within the extraembryonic fluid (Neubert et al., '71). In contrast to the PPP, production of lactate by the conceptuses was concomitantly reduced during diamide exposure, suggesting that overall metabolism of glucose via glycolysis may be inhibited. A dose of 100 $\mu \mathrm{M}$ diamide caused a slight, but insignificant, reduction in the production of lactate, whereas this product formation was significantly diminished to approximately $54 \%$ of control values by diamide concentrations of 250 and $500 \mu \mathrm{M}$. The results shown in Table 1 also indicate that concentrations greater than $250 \mu \mathrm{M}$ cause no further significant effects on these two metabolic pathways.

For study of the importance of thiol status for glycolysis, changes in total lactate content were determined in conceptuses cultured in the media containing diamide, $N$-ethylmaleimide (NEM), and L-buthionine(S,R)-sulfoximine (BSO). Exposure to diamide (500 $\mu \mathrm{M})$, a thiol oxidant shown to selectively oxidize GSH (Hiranruengchok and Harris, '93), resulted in a significant reduction of lactate levels to approximately $50 \%$ of control following a 30-min treatment (Fig. 1A). This result is in agreement with the inhibition of lactate production shown in Table 1. Exposure of the conceptuses to NEM $(100 \mu \mathrm{M})$, an alkylating agent known to block intracellular thiols, similarly decreased lactate levels (Fig. 1B). However, under the same exposure conditions, conceptuses cultured in the presence of BSO ( $1 \mathrm{mM}$ ), a GSH depletor that inhibits $\gamma$-glutamylcysteine synthetase but does not cause an increase in GSSG (Harris et al., 1986), did not significantly alter lactate production throughout the 5-hr incubation period when compared to control conceptuses. Lactate levels in the conceptuses continued to increase during the 5-hr culture period in both control and BSO treatment groups (Fig. 1C). Previous studies have demonstrated that under the same experimental conditions BSO ( $1 \mathrm{mM}$ ) did not produce dysmorphogenic effects to the cultured conceptus following 26-hr exposure at GD 10 (Hiranruengchok and Harris, '93), although GSH levels of the exposed conceptus were shown to decrease significantly (Harris et al., '86). Owing to a lack of thiol 
TABLE 1. Effects of diamide on pentose phosphate shunt pathway (PPP) and glycolysis in rat conceptuses (day 10) following a 1-hr exposure in culture medial

\begin{tabular}{lccc} 
& & \multicolumn{2}{c}{ Glycolysis (lactate production) } \\
\cline { 3 - 4 } Treatment & PPP $\left(\mathrm{CO}_{2}\right.$ production$)$ & Media & Whole conceptus \\
\hline Control & $14 \pm 2$ & $874 \pm 119$ & $248 \pm 65$ \\
$50 \mu \mathrm{M}$ diamide & $22 \pm 3$ & $\mathrm{~N} . \mathrm{D}$ & $\mathrm{N} . \mathrm{D}$. \\
$100 \mu \mathrm{M}$ diamide & $36 \pm 6^{*}$ & $735 \pm 81$ & $205 \pm 58$ \\
$250 \mu \mathrm{M}$ diamide & $45 \pm 7^{*}$ & $479 \pm 50^{*}$ & $108 \pm 22^{*}$ \\
$500 \mu \mathrm{M}$ diamide & $40 \pm 6^{*}$ & $471 \pm 62^{*}$ & $90 \pm 24^{*}$ \\
\hline
\end{tabular}

${ }^{1}$ Following a 1-hr incubation of conceptuses in the presence of $\left[{ }^{14} \mathrm{C}\right]$-glucose in control or diamide-supplemented media, product formation from metabolism of glucose via glycolysis and the pentose phosphate shunt pathway were determined. $\mathrm{U}-\left[{ }^{14} \mathrm{C}\right]$-glucose and $1-\left[{ }^{14} \mathrm{C}\right]-$ glucose were used in determination of lactate and $\mathrm{CO}_{2}$ production, respectively. Values are means $\pm \mathrm{SE}$ (nmoles/mg protein) of 3-4 samples from three replicate experiments.

$*$ Statistically significant from control $(P \leq 0.05)$

groups in the molecular structure of lactate, a direct interaction with NEM leading to the observed decreases in lactate levels is very unlikely. Direct interactions between diamide and lactate have been examined but do not appear to occur (data not shown).

Observations that diamide affects the PPP and lactate production in organogenesis stage conceptuses have prompted studies to determine whether diamide could alter other enzymes catalyzing the metabolic reactions in these pathways. As a result of the demonstration of differential effects of diamide on GSH oxidation and protein-S-SG formation (Hiranruengchok and Harris, '93, '95), the enzymatic activities were determined in tissue supernatants from embryo and VYS separately, following incubation of the conceptuses with the chemical for 30-60 min. The effects of diamide on the G6PD activities in conceptuses are shown in Table 2. Only small increases in activities were obtained with increasing concentrations of diamide, with the greater effects seen in the VYS.

GPD and PFK, two important enzymes of the glycolytic pathway, were also chosen as possible contributors to observed changes in lactate production. The control activities and percent changes elicited by diamide exposure are shown in Table 3. These enzymes contain thiol groups essential for their catalytic activities. Both GPD and PFK activities of the embryo were approximately 1.3 and 1.8 times higher than those of the VYS in untreated controls, respectively. It was the enzymatic activities in the VYS, and not the embryo, that were most greatly affected by NEM $(100 \mu \mathrm{M})$ or diamide. Rapid inactivation of GPD by NEM suggests that thiol groups are required for its catalytic function as demonstrated previously (Malhotra et al., '93). A diamide dose of $250 \mu \mathrm{M}$ only slightly reduced the GPD and PFK activities (approximately $20-30 \%$ inhibition) in the VYS over a 60 -min treatment period. More than $50 \%$ of both enzymatic activities in the VYS were inhibited by diamide $(500 \mu \mathrm{M})$. The inactivation of GPD by diamide was found to be reversible. Recovery of GPD activity in VYS that had been inhibited by a 30- min diamide $(500 \mu \mathrm{M})$ exposure was observed when the treated conceptuses were removed and cultured in normal media not containing diamide (Fig. 2). This effect was enhanced when the conceptuses were subsequently treated with dithiothreitol (a thiol reducing agent, 30 $\mathrm{mM}$ ), indicating that disulfide bonds are involved in the inhibition of GPD by diamide. Moreover, $100 \%$ of conceptuses exposed to diamide at a concentration of $500 \mu \mathrm{M}$ exhibited a collapse of the amnion and a disappearance of the amniotic cavity within 15-20 min of exposure (Fig. 3), which may contribute to dysmorphogenesis in diamide-exposed conceptuses. These similar effects was also observed in conceptuses exposed to a concentration of $250 \mu \mathrm{M}$ diamide, but not $100 \mu \mathrm{M}$ or lower.

\section{DISCUSSION}

The redox status of glutathione (GSH) and protein thiols has been shown to be altered in organogenesisstage rat conceptuses (gestational day 10) cultured in diamide-containing media, and the elicited changes in thiol status are accompanied by overt embryotoxicity (Hiranruengchok and Harris, '93). The present work shows that the changes in GSH and protein thiol status elicited by diamide were further associated with altered glucose metabolism in the developing rat conceptus undergoing organogenesis.

The effects of diamide on glucose metabolism were determined using measurements of lactate production and content by the conceptus. Lactate is the end product of glycolysis which has been determined to be the major active metabolic pathway at the stages of development studied (Shepard et al., '70; Tanimura and Shepard, '70; Freinkel et al., '84). Lactate concentrations remain constant within the untreated conceptus while levels in the culture medium increase over time, indicating a free efflux from the conceptus into the culture medium. Steady-state concentrations are maintained in the intact conceptus through a balance of glycolytic activity and lactate efflux. The total de- 
TABLE 2. Effects of diamide on glucose 6-phosphate dehydrogenase activity in the rat embryo and visceral yolk sac, $G D^{1}$

\begin{tabular}{lccc}
\hline & & \multicolumn{2}{c}{ G6PD activity (\% control) } \\
\cline { 4 - 4 } Treatment & Incubation time (min) & Embryo & VYS \\
\hline $100 \mu \mathrm{M}$ diamide & 30 & $110 \pm 8(5)$ & $124 \pm 15(5)$ \\
& 60 & $99(2)$ & $108(2)$ \\
$250 \mu \mathrm{M}$ diamide & 30 & $120 \pm .4(4)^{*}$ & $155 \pm 19(5)^{*}$ \\
$500 \mu \mathrm{M}$ diamide & 60 & $108 \pm 1(3)$ & $132 \pm 6(3)$ \\
& 30 & $128 \pm 8(6)$ & $155 \pm 11(6)$ \\
& 60 & $112 \pm 2(3)$ & $146 \pm 12(3)^{*}$ \\
\hline
\end{tabular}

${ }^{1}$ Control G6PD activity $=12.9 \pm 1.0$ (embryo, $30 \mathrm{~min}$ ); $11.2 \pm 1.1(\mathrm{VYS}, 30 \mathrm{~min}) ; 11.7 \pm 0.6$ (embryo, $60 \mathrm{~min}) ; 9.4 \pm 0.6\left(\mathrm{VYS}, 60 \mathrm{~min}\right.$ ) $\mathrm{nmoles} \mathrm{NADP}^{+}$used $/ \mathrm{min} / \mathrm{mg}$ protein. Values are means \pm SE (n).

*Statistically significant difference from control $(P \leq 0.05)$.

TABLE 3. Effects of $\boldsymbol{N}$-ethylmaleimide (NEM) and diamide on glyceraldehyde 3-phosphate dehydrogenase and phosphofructokinase (PFK) activities in the rat embryo and visceral yolk sac, GD $10^{1}$

\begin{tabular}{|c|c|c|c|c|c|}
\hline \multirow[b]{2}{*}{ Treatment } & \multirow[b]{2}{*}{ Incubation time (min) } & \multicolumn{2}{|c|}{ GPD activity (\% control) } & \multicolumn{2}{|c|}{ PFK activity (\% control) } \\
\hline & & Embryo & VYS & Embryo & VYS \\
\hline $100 \mu \mathrm{M}$ NEM & $\begin{array}{r}5 \\
15\end{array}$ & $\begin{array}{l}99 \pm 5(3) \\
91 \pm 10(4)\end{array}$ & $\begin{array}{c}54 \pm 15^{*}(3) \\
5 \pm 2 *(4)\end{array}$ & $\begin{array}{l}\text { N.D. } \\
\text { N.D. }\end{array}$ & $\begin{array}{l}\text { N.D. } \\
\text { N.D. }\end{array}$ \\
\hline $100 \mu \mathbf{M}$ diamide & 30 & $110 \pm 1(6)$ & $126 \pm 9(6)$ & $97(2)$ & $102(2)$ \\
\hline & 60 & $101 \pm 9(4)$ & $101 \pm 4(4)$ & $100 \pm 6(3)$ & $98 \pm 7(3)$ \\
\hline $250 \mu \mathrm{M}$ diamide & 30 & $122 \pm 15(6)$ & $83 \pm 8(6)$ & $93 \pm 5$ & $86 \pm 6(3)$ \\
\hline $500 \mu \mathrm{M}$ diamide & $\begin{array}{l}60 \\
30\end{array}$ & $\begin{array}{r}96 \pm 18(4) \\
123 \pm 13(6)\end{array}$ & $\begin{array}{l}69 \pm 2^{*}(4) \\
50 \pm 5^{*}(10)\end{array}$ & $\begin{array}{l}96 \pm 7(3) \\
95 \pm 5(3)\end{array}$ & $\begin{array}{l}77 \pm 1^{*}(3) \\
77+5(3)\end{array}$ \\
\hline & 60 & $72 \pm 8^{*}(4)$ & $22 \pm 2^{*}(4)$ & $102 \pm 9(3)$ & $43 \pm 4^{*}(3)$ \\
\hline
\end{tabular}

${ }^{1}$ Control GPD (embryo) $=306.0 \pm 20.7(\mathrm{n}=10) ;$ control GDP $(V Y S)=238.7 \pm 20.5(\mathrm{n}=14) \mathrm{nmoles} \mathrm{NADH} \mathrm{used} / \mathrm{min} / \mathrm{mg}$ protein control PFK (embryo) = 60.5 $\pm 4.1(\mathrm{n}=6)$; control PFK (VYS) $=33.5 \pm 2.1(\mathrm{n}=6) \mathrm{nmoles} \mathrm{NADH} \mathrm{used} / \mathrm{min} / \mathrm{mg}$ protein. No significant difference between control values at 30 and 60 min of incubation. Values are means \pm SE (n).

*Statistically significant differences from control $(P \leq 0.05)$.

creased lactate production caused by direct inhibition of the glycolysis pathway (anaerobic metabolism of glucose to pyruvate) and/or a decrease in the NADH-dependent reduction of pyruvate to lactate is manifest as a decreased lactate content in both the conceptus and culture medium (Table 1, Fig. 1).

The differential inhibition of glycolysis pathway enzymes GPD and PFK by diamide (Table 3) is correlated with the difference in magnitude of GSH oxidation (Hiranruengchok and Harris, '93) and increased protein-S-SG formation between the embryo and VYS (Hiranruengchok and Harris, '95), suggesting a role of the VYS in mediating embryotoxicity due to altered GSH-associated cellular functions. The enzyme GPD was very sensitive to the thiol alkylating agent NEM, and its inactivation confirmed the importance of thiol groups for catalytic activity. Under the same controlled experimental conditions, PFK was found to have lower specific activities and was less sensitive to diamide. The susceptibility of GPD activity to inhibition by oxidative stress has been previously investigated in cultured human lung carcinoma cells (Brodie and Reed, '90) and human endothelial cells (Schuppe-Koistinen et al., '94) after hydroperoxide treatment. These studies, however, reported that diamide did not cause S-thiolation of GDP and/or failed to inhibit the enzyme activ- ity. This effect may be partially due to differences in cell type and culture conditions.

The activity of GPD in the VYS was restored when diamide was removed and the effect was enhanced by subsequent addition of a high concentration of dithiothreitol, a thiol reducing agent, (DTT, $30 \mathrm{mM}$ ), further supporting the involvement of disulfide exchange in diamide-modification of GPD activity. Previous studies in our lab have shown that recovery of GPD activity occurred concomitantly with the reduction in proteinS-SG, and that the recovery was also potentiated by D'T treatment (data not shown). The failure to show a significant acceleration in the rate of reduction of protein-S-SG following DTT (1 $\mathbf{~ m M})$ treatment (Hiranreungchok and Harris, '95) is likely related to the lower doses used in the protein-S-SG study and also may reflect a differential reduction potential between GPD and other proteins.

It is believed that $\mathrm{S}$-thiolation of the reactive thiol groups of the enzyme by GSSG via reversible thioldisulfide interchange reactions to form protein-S-SG is responsible for the enzyme inactivation by diamide. However, modification of the reactive thiols of the enzyme by direct oxidation of the protein thiols by diamide to form mixed disulfide or protein-protein disulfides without participation of GSSG cannot be ruled out 


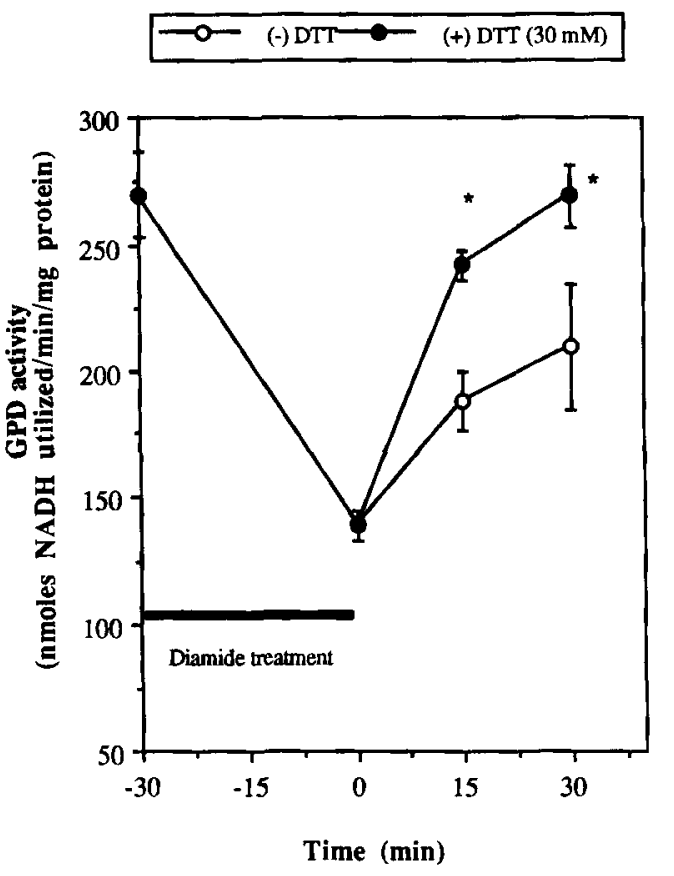

Fig. 2. Recovery of glyceraldehyde 3-phosphate dehydrogenase (GPD) activity in the visceral yolk sac (VYS) and effects of dithiothreitol (DTT, $30 \mathrm{mM}$ ). Conceptuses (GD 10) were previously incubated with diamide $(500 \mu \mathrm{M})$ in the culture media for $30 \mathrm{~min}$ to inhibit the enzymatic activity in the yolk sac (control GPD activity $=269.7 \pm$ $16.6 \mathrm{nmoles} \mathrm{NADH}$ oxidized $/ \mathrm{min} / \mathrm{mg}$ protein). After pretreatment with diamide, the conceptuses were removed from the media, rinsed with warm HBSS and recultured in fresh media with or without DTT. At times indicated, the conceptuses were removed, rinsed with icecold PBS and processed for the enzymatic activity assay as described in the method. Values are means $\pm S E(n=4)$. Asterisk (*), statistically significant difference from control $(P \leq 0.05)$.

(Baker and Hagner, '90). During a 5-hr exposure, GSH levels of the conceptus incubated with BSO were depleted (Harris et al., '87) to a comparable degree as those exposed to diamide $(500 \mu \mathrm{M}$, Hiranruengchok and Harris, '93). However, in contrast to the effects of NEM or diamide, no changes in the production of lactate were seen in BSO (1 mM) treated conceptuses. Levels of GSSG were not determined in these BSOtreated conceptuses, although, we have previously reported (Harris et al., '86) that GSH/GSSG ratios are not affected significantly in embryo and VYS during exposure to BSO (1 mM) for $24 \mathrm{hr}$ in culture. These observations suggest that the inhibition of lactate production seen in conceptuses incubated with the thiol oxidant diamide occur due to changes in cellular thiol/ disulfide status (increased GSSG and protein-S-SG formation) rather than to the direct effects of GSH depletion per se (Hiranruengchok and Harris, '93, '95). Alterations in the enzymatic activities, at least for GPD activity, and the resulting reduction in glycolysis are believed to be associated with changes in thioldisulfide status, although it is still also plausible that these effects may occur due to the acute toxicity of diamide (Hiranruengchok and Harris, '93). Alterations of other enzymatic activities in the pathway through S-thiolation, such as pyruvate kinase (Mannervik and Axelsson, '80) and changes in cofactors that regulate the pathway, decreasing the metabolism of pyruvate to lactate may also contribute to the observed decreases.

Exposure of the developing conceptus (GD 10) to diamide $(100-500 \mu \mathrm{M})$ also resulted in a concentrationdependent activation of glucose metabolism through the PPP. G6PD activity, a rate-limiting component of the PPP pathway, was only modestly activated following diamide exposure and did not correlate well with marked increases in the PPP activity under the same treatment conditions. These results indicate that mechanisms other than direct protein-S-SG formation, as suggested by Brigelius and Schult ('84), may be involved in enhancing PPP activity following diamide exposure. Regulation of the PPP via altered NADPH/ $\mathrm{NADP}^{+}$ratios is likely to occur (Eggleston and Krebs, '74; Brigelius and Schult, '84). Our previous studies have shown that the GSSG-reductase activity, especially in the VYS, plays an important role in maintenance of GSH and protein-S-SG levels during diamide exposure (Hiranruengchok and Harris, '93, '95). Significant amounts of NADPH, used as a cofactor for this enzyme and the subsequent decrease of NADPH/ $\mathrm{NADP}^{+}$ratios in diamide-exposed conceptuses, could be responsible for PPP activation. In addition, the direct oxidation of NADPH by diamide may also occur at high doses (Harris and Biaglow, '72) and lead to a rise in $\mathrm{NADPH}^{+}$. Stimulation of the PPP in diamide-exposed conceptuses will result from increased $\mathrm{NADP}^{+}$, which reverses the effects of the normal physiological inhibitor NADPH on G6PD activities (Eggleston and Krebs, '74; Brigelius and Schult, '84). A direct correlation between the increased PPP activity and proteinS-SG contents or changes in NADPH/NADP ${ }^{+}$in these conceptuses has not yet been confirmed. Moreover, inhibition of the glycolytic pathway by diamide may facilitate the flow of G6P to the PPP, contributing to the shift of glucose metabolism away from glycolysis and toward the PPP in order to increase production of NADPH. These results describe the potential role of the PPP in combination with GSSG-reductase in regeneration of GSH and control of cellular thiol status of the developing conceptus during oxidative conditions. Observed increases in the PPP activity of the conceptuses appeared to reach a plateau at a concentration of 250 $\mu \mathrm{M}$ diamide, implicating that the metabolic pathway was saturated and/or GSSG-reductase capacity was overwhelmed. A small reduction in the magnitude of $\mathrm{CO}_{2}$ production by the PPP suggested that cellular toxicity may also have occurred at some point during the 1-hr exposure to $500 \mu \mathrm{M}$.

Conceptuses exposed to diamide at concentrations of 250 and $500 \mu \mathrm{M}$ exhibit a rapid collapse of the amnion and disappearance of the amniotic cavity within 15-20 

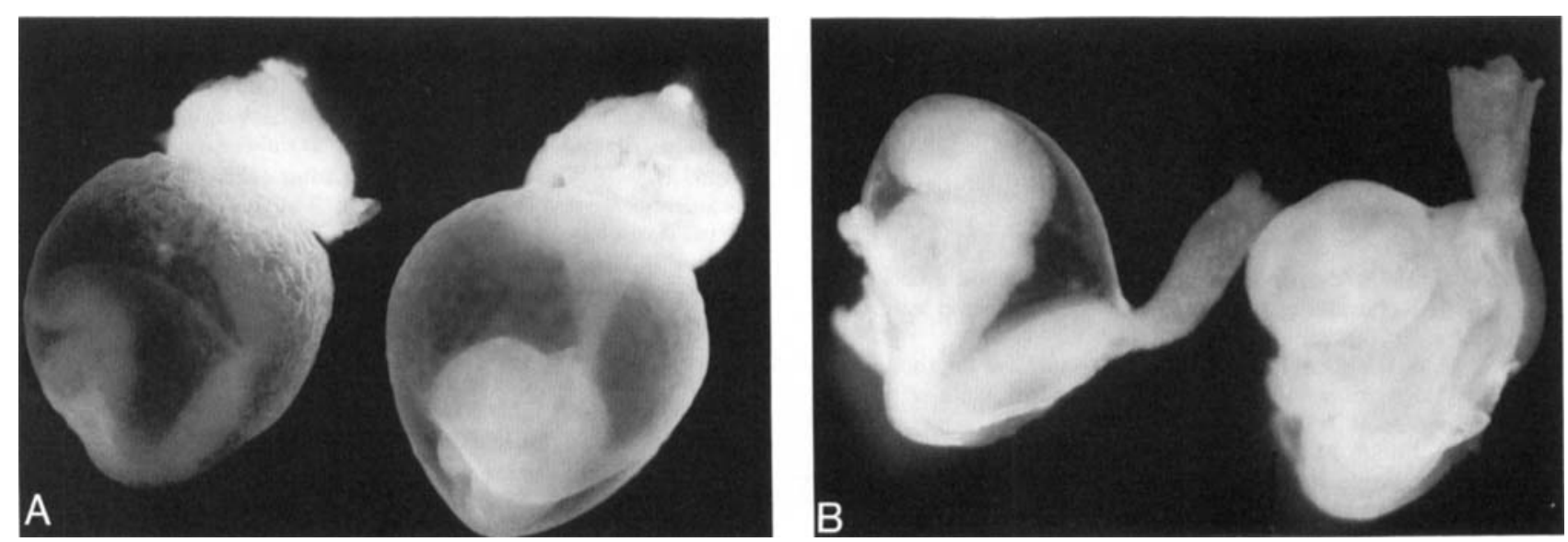

Fig. 3. Gestational day 10 rat conceptuses grown in whole embryo culture. A: shows a typical control (left) and diamide-treated (right; $500 \mu \mathrm{M}, 15 \mathrm{~min}$ ) conceptus in which the visceral yolk sacs have been left intact to show the relative similarity in overall growth and yolk sac dimensions. B: Embryos have had the visceral yolk sac removed to show the disappearance of amniotic fluid and physical constriction of the embryo by the amniotic membrane in the diamide-treated embryo on the right.

min of exposure. The VYS has been postulated to play an important role in regulating the volume of the extraembryonic fluid (Payne and Deuchar, '72). Studies by Chan and Wong ('78) have suggested the presence of an active $\mathrm{Na}^{+}-\mathrm{K}^{+}$pump located in the fetal side of the VYS (GD 17.5) and the possible role of this active $\mathrm{Na}^{+}$ transport in the formation of amniotic fluid. The activity of $\mathrm{Na}^{+}-\mathrm{K}^{+}$-ATPase, which is known to contain sensitive thiol groups, has been shown to be inhibited by GSSG (Dick et al., '69) and diamide (Pillion et al., '77). From this evidence, it is speculated that the effect of diamide on disappearance of the amniotic cavity may be due to an alteration of the VYS membrane ion transport function and a subsequent imbalance of fluid inflow through the VYS and amnion. The observation that vitelline vasculature within the diamide (250 and $500 \mu \mathrm{M})$ exposed VYS was also reduced may indicate impairment of the VYS membrane structure in support the above hypothesis. Amniotic fluid volume of the rat conceptus increases 10-fold between GD 10 and 11 (Park and Shepard, '94) and may be an important factor in facilitating the proper rotation of the embryonic axis. It is likely that a physical constraint due to reduced amniotic fluid volume or complete collapse of the amnion are a crucial factors leading to the abnormal axial rotation observed in conceptuses following shortterm exposure to $500 \mu \mathrm{M}$ diamide (Hiranruengchok and Harris, '83). Moreover, it has been suggested by Park and Shepard ('94) that the amniotic cavity is one of the main entry routes for glucose into the embryo during a period of early organogenesis. Therefore, the glycolytic activity of the embryo may be limited by the deprivation of the glucose supply, contributing to observed decreases in lactate production by the conceptuses (Table 1). It is not yet known whether decreases in the synthesis of lactate by the conceptus were due to differential inhibition of glycolysis in the embryo or VYS. Higher activities of both GPD and PFK found in the tissue supernatants from the embryo when compared to those from the VYS implies the higher glycolysis activity and more energy required by the embryo. This was in concordance with studies by Hunter and Sadler ('89), in which mouse conceptuses were found to have larger amounts of lactate produced by the embryo in comparison to the VYS and ectoplacental cone under normal conditions.

Results from this study show the importance of conceptal glutathione redox status in regulation of glucose metabolism via glycolysis and the PPP during oxidative stress. The inhibition of glycolysis appears to be a result of thiol oxidation, likely as a result of direct S-thiolation of the critical enzymes while the effects on PPP activation are due to indirect changes in pyridine nucleotide redox status. Because of the physiological association of the VYS and the embryo, the greater effects of diamide observed in the VYS relative to the embryo proper indicated that diamide-induced embryotoxicity may occur secondary to initial alterations of VYS functions.

\section{ACKNOWLEDGMENTS}

We thank Dr. Jeffrey Ambroso, Eunyong Lee, SaraJane Larsen, Dr. Tamara McNutt, Rita Berberian, and Bjorn Thorsrud for their technical assistance and constructive suggestions during this research, and Dr Isadore Bernstein for access to laboratory instrumentation essential for this project. This study was supported by the grant from NIH (ES 05235) and funds provided by the Office of the Vice President of Research at the University of Michigan. 


\section{LITERATURE CITED}

Baker, M.A., and B.A. Hagner (1990) Diamide induced shift in protein and glutathione thiol:disulfide status delays DNA rejoining after X-irradiation of human cancer cells. Biochim. Biophys. Acta, 1037: $39-47$.

Barker, S.B., and W.H. Summerson (1941) The colorimetric determination of lactic acid in biological material. J. Biol. Chem., 138:535554.

Birkett, D.T. (1973) Mechanism of inactivation of rabbit muscle glyceraldehyde-3-phosphate dehydrogenase by ethacrynic acid. Mol. Pharmacol., 9:209-218.

Bradford, M.M. (1976) A rapid and sensitive method for the quantitation of microgram quantities utilizing the principle of proteindye-binding. Anal. Biochem., 72:248-254.

Brigelius, R. (1985) Mixed disulfides: Biological functions and increase in oxidative stress. In: Oxidative Stress. H. Sies, ed. Academic Press, London, pp. 243-272.

Brigelius, R., and E. Schult (1984) The role of hepatic NADP ${ }^{+}$and glutathione status altered by oxidative stress in the regulation of pentose phosphate cycle. Life. Chem. Rep. Suppl., 2:277-283.

Brigelius, R. (1983) Glutathione oxidation and activation of pentose phosphate cycle during hydroperoxide metabolism. A comparison of livers from fed and fasted rats. Hoppe-Seylers Z. Physiol. Chem., 364:989-996.

Brodie, A.E., and D.J. Reed (1990) Cellular recovery of glyceraldehyde-3-phosphate dehydrogenase activity and thiol status after exposure to hydroperoxides. Arch. Biochem. Biophys., 276:212-218.

Chan, S.T.H., and P.Y.D. Wong (1978) Evidence of active sodium transport in the visceral yolk sac of the rat in vitro. J. Physiol. (Lond.), 279:385-394.

Dick, D.A.T., E.G. Dick, and D.C. Tosteson (1969) Inhibition of adenosine triphosphatase in sheep red cell membranes by oxidized glutathione J. Gen. Physiol., 54:123-133.

Eggleston, L.V., and H. Krebs (1974) Regulation of the pentose phosphate cycle. Biochem. J., 138:425-435.

Freeman, S.J., F. Beck, and J.B. Lloyd (1981) The role of the visceral yolk sac in mediating protein utilization by rat embryos cultured in vitro. J. Embryol. Exp. Morphol., 66:223-234.

Freinkel, N., N.J. Lewis, S. Akazawa, S.I. Roth, and L. Gorman (1984) The honeybee syndrome: Implications of the teratogenicity of mannose in rat-embryo culture. N. Eng. J. Med. 310:223-230.

Gilbert, H.F. (1982) Biological disulfides: The third messenger? Modulation of phosphofructokinase activity by thiol/disulfide exchange J. Biol. Chem., 257:12086-12091.

Gilbert, H.F. (1984) Redox control of enzyme activity by thiol/disulfide exchange. Methods Enzymol., 107:330-351.

Harris, C., M.J. Namkung, and M.R. Juchau (1987) Regulation of intracellular glutathione in rat embryos and visceral yolk sacs and its effect on 2-nitrosofluorene-induced malformations in the whole embryo culture system. Toxicol. Appl. Pharmacol., 88:141-152.

Harris, C., A.G. Fantel, and M.R. Juchau (1986) Differential glutathione depletion by L-buthionine-S,R-sulfoximine in rat embryo versus visceral yolk sac in vivo and in vitro. Biochem. Pharmacol., 35:4437-4441.

Harris, J.W., and J.E. Biaglow (1972) Non-specific reactions of the glutathione oxidant "Diamide" with mammalian cells. Biochem. Biophys. Res. Commun., 46:1743-1748.

Harris, C., K.L. Stark, and M.R. Juchau (1988) Glutathione status and the incidence of neural tube defects elicited by direct acting teratogens in vitro. Teratology, 37:577-590.

Hiranruengchok, R., and C. Harris (1993) Glutathione oxidation and embryotoxicity elicited by diamide in the developing rat conceptus in vitro. Toxicol. Appl. Pharmacol., 120:62-71.

Hiranruengchok, R., and C. Harris (1995) Characterization of protein-glutathione mixed disulfides in the developing rat conceptus following diamide treatment in vitro. Teratology, 52:196-204.

Horton, W.E., T.W. Sadler, and E.S. Hunter (1985) Effects of hyperketonemia on mouse embryonic and fetal glucose metabolism in vitro. Teratology, 31:227-233.

Hunter E.S. III, and T.W. Sadler (1989) Fuel-mediated teratogenesis: Biochemical effects of hypoglycemia during neurulation in mouse embryos in vitro. Am. J. Physiol., 257 (Pt. 1):E269-E276.

Jones, T.W., H. Thor, and S. Orrenius (1986) Cellular defense mechanisms against toxic substances. Arch. Toxicol., Suppl., 9:259-271.

Kosower, N.S., and E.M. Kosower (1978) The glutathione status of cells. Int. Rev. Cytol., 54:109-160.

Lee, C-Y. (1982) Glucose-6-phosphate dehydrogenase from mouse. Methods Enzymol., 89:252-257.

Levy, H.R., and M. Christoff (1983) A critical appraisal of the effect of oxidized glutathione on hepatic glucose-6-phosphate dehydrogenase activity. Biochem. J., 214:959-965.

Lloyd, J.B. (1990) Cell physiology of the rat visceral yolk sac: A study of pinocytosis and lysosome function. Teratology, 41:383-393.

Malhotra, O.P., D.K. Srivastava, A.M. Kayastha, and Srinivasan. (1993) Inactivation of glyceraldehyde-3-phosphate dehydrogenase with SH-reagent and its relationship to the protein quaternary structure. Indian J. Biochem. Biophys., 30:264-269.

Mannervik, B. and K. Axelsson (1980) Role of cytoplasmic thioltransferase in cellular regulation by thiol-disulfide interchange. Biochem. J., 190:125-130.

May, J.M. (1981) The role of glutathione in rat adipocyte pentose phosphate cycle activity. Arch. Biochem. Biophys., 207:117-127.

Neubert, D., H. Peters, S. Teske, E. Kohler, and H.-J. Barrach (1971) Studies on the problem of "Aerobic glycolysis" occurring in mammalian embryos. Naunyn. Schmiedeberg Arch. Pharmakol., 268: 235-241.

Park, H.W. and T.H. Shepard (1994) Volume and glucose concentration of rat amniotic fluid: Effects on embryo nutrition and axial rotation. Teratology, 49:465-469.

Passonneau, J.V. (1974) L-(+)-Lactate: Determination with lactate dehydrogenase and NAD by fluorimetric method. Methods Enzymatic Anal., 3:1468-1472.

Payne, G.S., and E.M. Deuchar (1972) An in vitro study of functions of embryonic membranes in the rat. J. Embryol. Exp. Morphol., 27:533-542.

Pillion, D.J., L. Moree, H. Rocha, D.H. Pashley, J. Mendicino, and F.H. Leibach (1977) The role of glutathione in renal cortical tissue. Effects of diamide on $\mathrm{Na}^{+}$and GSSG levels, amino acid transport and $\mathrm{Na}^{+}-\mathrm{K}^{+}$-ATPase activity. Mol. Cell. Biochem., 18:109-115.

Schuppe-Koistinen, I., P. Moldeus, T. Bergman, and I.A. Cotgreave (1994) S-thiolation of human endothelial cell glyceraldehyde-3phosphate dehydrogenase after hydrogen peroxide treatment. Eur. J. Biochem., 221:1033-1037.

Shepard, T.H., T. Tanimura, and M.A. Robkin (1970). Energy metabolism in early mammalian embryos. Devl. Biol., Suppl., 4:42-58.

Tanimura, T. and T.S. Shepard (1970). Glucose metabolism by rat embryos in vitro. Proc. Soc. Exp. Biol. Med., 135:51-54.

Wong, M., L.M.J. Helston, and P.G. Wells (1989) Enhancement of murine phenytoin teratogenicity by the gamma-glutamylcysteine synthetase inhibitor L-buthionine-(S,R)-sulfoximine and by the glutathione depletor diethyl maleate. Teratology, 40:127-141. 